\title{
Traffic Air Pollution and Respiratory Health: A Cross-Sectional Study among Bus Drivers in Dakar (Senegal)
}

\author{
Fatou K. Sylla ${ }^{*}$, Adama Faye ${ }^{1}$, Mor Diaw ${ }^{2}$, Mamadou Fall ${ }^{3}$, Anta Tal-Dia1 \\ ${ }^{1}$ Institute of Health and Development-Public Health and Preventive Medecine, Cheikh Anta Diop University (UCAD), Dakar, Senegal \\ ${ }^{2}$ Laboratory of Physiology and Functional Explorations, University of Cheikh Anta Diop, Dakar, Senegal \\ ${ }^{3}$ Laboratory of Toxicology and Hydrology, Cheikh Anta Diop University (UCAD), Dakar, Senegal \\ Email: *f.sylla@outlook.fr, adamafaye94@gmail.com, romdiaw@gmail.com, madoufal@gmail.com, adia@ised.sn
}

How to cite this paper: Sylla, F.K., Faye, A., Diaw, M., Fall, M. and Tal-Dia, A. (2018) Traffic Air Pollution and Respiratory Health: A Cross-Sectional Study among Bus Drivers in Dakar (Senegal). Open Journal of Epidemiology, 8, 1-13.

https://doi.org/10.4236/ojepi.2018.81001

Received: October 11, 2017

Accepted: January 8, 2018

Published: January 11, 2018

Copyright $\odot 2018$ by authors and Scientific Research Publishing Inc. This work is licensed under the Creative Commons Attribution International License (CC BY 4.0).

http://creativecommons.org/licenses/by/4.0/

\begin{abstract}
Introduction: Road traffic exposes bus drivers to the detrimental effects of air pollutants on respiratory health. This study determined the frequency of chronic respiratory illnesses and its related factors among bus drivers in Dakar, Senegal. Methods: This study had a cross-sectional design conducted in a total of 178 bus drivers in Dakar, Senegal. A questionnaire was used to inquire about socio-economic characteristics, occupational factors and respiratory symptoms of bus drivers. Lung function tests were used to determine the presence of asthma and Chronic Obstructive Pulmonary Disease (COPD). The relationship between our variables of interest and respiratory diseases was determined by logistic regression analysis. Results: The results of the study show that $57.9 \%$ of bus drivers had a chronic cough, and $65.7 \%$ had recurrent cold. Lung function tests showed that $38.8 \%$ of bus drivers had asthma and $30.3 \%$ COPD. Multivariate analysis found that recurrent cold increased the risk of asthma $(\mathrm{OR}=6.3,95 \% \mathrm{CI}: 1.12-35.79)$ and $\mathrm{COPD}(\mathrm{OR}=7.7,95 \% \mathrm{CI}$ : 1.14 - 52.8). The respiratory health status of bus drivers depended on the work area $(\mathrm{OR}=3.2,95 \% \mathrm{CI}: 1.13$ - 9.31). Conclusion: The respiratory symptoms and illnesses observed among bus drivers are associated with their exposure to air pollutants from road traffic.
\end{abstract}

\section{Keywords}

Air Pollution, Bus Drivers, Asthma, COPD, Senegal

\section{Introduction}

Air pollution from cars is the main source of pollution in big African cities [1]. 
Road traffic has the potential to significantly increase emissions of pollutants such as carbon monoxide, oxides of nitrogen, particulate matter, and hydrocarbons. These pollutants can induce harmful effects on health [2] [3] [4] [5]. Inhalation represents the fundamental mechanism of exposure to pollutants in humans [6] [7] [8]. Consequently, the respiratory system becomes a primary target of the adverse effects of air pollution [9]. Chronic respiratory diseases can have environmental causes such as exposure to air pollution [10]. Studies have shown that chronic exposure to air pollutants is associated with the development and aggravation of chronic respiratory diseases, particularly asthma and Chronic Obstructive Pulmonary Disease (COPD) [9].

Chronic respiratory diseases are affecting more and more people in the world. The WHO has estimated 235 million people with asthma and 64 million people with COPD worldwide [10]. Many studies have shown that some people are more exposed than others to air pollution due to their professional activity [6]. Bus drivers are exposed to large quantities of ambient air pollutants when they drive on busy roads or when they find themselves in congestion, bus stops or industrial areas. Studies have shown a reduction in lung function in workers who are highly exposed to air pollution from road traffic [6] [11] [12].

In Africa, unlike developed countries, little research has been done on the respiratory health of workers who are highly exposed to air pollution from cars. These studies were largely conducted among traffic police [13] [14]. However, the morbidity and mortality of chronic respiratory diseases are high in developing countries. Thus, chronic respiratory diseases have been shown to be the third cause of death in these countries [10]. In Senegal, the prevalence of asthma is $13 \%$ in urban areas compared to $6 \%$ in rural areas [15]. Air pollution is suspected to be one of the main causes of the rise in chronic respiratory diseases recorded recently in Dakar. As in most developing countries, road traffic is responsible for up to $90 \%$ of air pollution in the Senegalese capital [16]. Dakar faces a growing urbanization with an increase in the car fleet. The Senegalese car fleet was estimated at 401,910 vehicles in 2013 , compared with 289,808 vehicles in 2009 . The $72.8 \%$ of Senegal's fleet of vehicles (292,590 vehicles) circulate in Dakar [17]. This implies more transport within the city and consequently more air pollution from road traffic [18]. In Senegal, chronic respiratory diseases following occupational exposure have been poorly studied. Studies on the respiratory health effects of outdoor air pollution have not yet been carried out among bus drivers despite their high level of exposure.

The purpose of this study is to obtain data on respiratory health status of bus drivers in order to advocate and adopt targeted strategies to protect them and the population from the deleterious effects of air pollution from road traffic. This study aimed to assess the respiratory health of bus drivers exposed to chronic air pollution in Dakar city.

\section{Methods}

\subsection{Setting}

The study was conducted mainly in the urban areas of Dakar city. The neigh- 
borhoods of Medina, HLM and Petersen were chosen as the areas for our study. These neighborhoods include the busiest roads in the city of Dakar and thus record very dense road traffic. These sites include the main Dakar bus stations and each houses a roadside measuring station for air quality.

\subsection{Study Design and Population}

The design of this study was a cross-sectional study for analytical purposes, which lasted three months (September to November 2016) on a sample of bus drivers working in public transport. Bus drivers within the neighborhoods HLM, Medina and Petersen were approached. The selection of the bus drivers was conducted by the following inclusion criteria:

1) Be at least 18 years of age;

2) Have completed at least two years working as bus driver;

3) Have signed the informed consent of the participant.

Bus drivers who met all inclusion criteria were involved in the study. On the other hand, bus drivers who had a chest condition that did not permit lung function tests by spirometry such as the presence of chest, abdominal or dental pain were excluded from the study.

\subsection{Sampling}

The Schwartz formula [19] adapted to cross-sectional studies was used for the determination of the sample size.

$$
n=(z)^{2} p(1-p) / d^{2}
$$

$n=$ sample size to be determined; $z=$ confidence interval $(95 \%) ; p=$ prevalence of the studied pathology; $d=$ margin of error (5\%).

Asthma is a main outcome in our study, its prevalence of $13 \%$ in Dakar city was used for the determination of the sample size. A sample of 178 bus drivers was obtained to have a representative sample.

\subsection{Questionnaire}

A questionnaire was designed for this study. The questionnaire included questions on socio-economic characteristics, respiratory symptoms (cough, nose irritation, wheezing, rhinorrhea, nasal congestion, etc.), smoking, occupational exposure (duration of the job, working days and hours per week and exposure to other sources of pollution other than air pollution from cars). The questions on respiratory symptoms were inspired by the questionnaire of the American Thoracic Society (ATS) [20]. The questionnaire was formulated to provide information on a period of 12 months before the study period.

\subsection{Measures}

\subsubsection{Anthropometric Measures}

Anthropometric parameters such as weight $(\mathrm{Kg})$ and height $(\mathrm{m})$ were measured according to the World Health Organization standard protocols [21]. The Body 
Mass Index (BMI) was obtained by the ratio: weight $(\mathrm{Kg}) /$ height $\left(\mathrm{m}^{2}\right)$. A BMI of $<18.5$ was regarded as underweight, 18.5 - 24.9 normal, 25 - 29.9 overweight and $\geq 30$ obese.

\subsubsection{Pulmonary Function Measurements}

Lung function tests were conducted by spirometry by using a Mir Spirobank II Spirometer (MIR Medical International Research, Rome, Italy). Spirometry tests identified any obstructive or restrictive syndrome in bus drivers. Qualified personnel executed spirometric examinations in the morning between 9 - 12 hours. Lung function tests were performed in a seated position and with a nose clip as recommended by the American Thoracic Society (ATS) [22] [23] [24]. Each bus driver performed three times each of the lung tests where the best value was retained. Spirometric data from bus drivers were compared to the predicted values of non-smoking adult males with the same characteristics as ethnicity, age, sex, and height [25]. Spirometric parameters such as forced expiratory volume in one second (FEV1), forced vital capacity (FVC), tiffeneau index (FEV1/FVC), peak expiratory flow (PEF) and expiratory flow from $25 \%-75 \%$ of the vital capacity (DEM 25\% - 75\%), were studied for each participant. Restrictive syndrome was defined as a decrease in total vital capacity less than $80 \%$ of the predicted values and a normal tiffeneau index higher than $70 \%$ of the predicted value. Obstructive syndrome was defined by a tiffeneau index (FEV1/FVC) of less than $70 \%$ of the predicted value [26]. A reversibility test was performed in all bus drivers with obstructive syndrome to determine if the obstruction was reversible or not. The reversibility test is used to discern asthma from other obstructive diseases such as COPD. A dose of $200 \mathrm{~mL}$ of sabutalmol was administered to the bus driver with an obstructive syndrome (ventoline pump and inner tube), and then about fifteen minutes later, a new FVC test was performed. The obstruction was considered reversible if the difference between pre- and post-bronchodilator FEV1 or FVC was greater than $12 \%$ and $200 \mathrm{ml}$. The spirometric measurements were interpreted by blind evaluation by a pulmonologist for the final report.

\subsubsection{Outcomes Measurement}

COPD was diagnosed in bus drivers with a non-reversible obstructive syndrome after bronchodilator determined by spirometry with a Tiffeneau index (FEV1/ FVC) of less than 0.7. COPD is classified according to its severity by the GOLD report [27]. Asthma was defined by clinical symptoms of the disease such as coughing, wheezing and dyspnea, and by spirometric tests with a positive reversibility of the obstruction by an increase of at least $12 \%$ value of FEV1 or FVC [28].

\subsection{Statistical Analyses}

Firstly, a descriptive analysis was conducted to describe the variables of the study. The qualitative variables were expressed in proportions. Quantitative variables were expressed as mean and standard deviation. Secondly, bivariate anal- 
ysis was performed. A comparison of proportions of the variables was carried out between the bus drivers according to their area of practice by the Chi- 2 test in order to find statistically significant differences. The association between the presence of respiratory illnesses as a dependent variable (asthma and COPD) and independent variables such as personal characteristics, occupational activity information (workplace, years of practice, exposure time, etc.) was also determined by a bivariate analysis. The Chi- 2 test was used for the crossing of the dependent variable and the independent qualitative variables. The crossing of the quantitative variables with the dependent variable was done with the Student test. Thirdly, a logistic regression analysis was done with the independent variables that had a $p<0.25$ in the bivariate analysis according to the Hosmer and Lemeshow postulate [29]. This analysis determined the relationship between respiratory diseases (asthma and COPD) and factors related to work and the working environment (working area, sources of pollution, number of worked per week etc.) in bus drivers. Statistical tests were considered significant with a $p$ $<0.05$. The R software (version 3.3.3) was used for statistical analysis.

\subsection{Ethical Approval}

This study received ethical approval from the Ethics and Research Committee (CER) of the University of Cheikh Anta Diop (UCAD), Dakar, Senegal. The code and date of ethical approval was Protocole 0090/2015/CER/UCAD, 08 January 2016.

\section{Results}

Bus drivers had a mean age of 34.8 years ( $\mathrm{SD}=10.1$ years). They had an average 12.4 years ( $\mathrm{SD}=8.3$ years) of work as bus driver. The results found no significant differences in age, BMI, duration in the work among bus drivers regardless their working area (Table 1). Most of the bus drivers (46.6\%) had no education compared to $15.2 \%$ of bus drivers who reached secondary school. Among bus drivers interviewed, $54.5 \%$ were married. There are no statistically significant differences in the level of education and marital status between bus drivers in their working area (Table 1). However, there are statistically significant differences between the bus drivers according to their working area for the duration in the workplace $(p=0.02)$, the number of working days per week $(p<0.001)$, the transit time per day $(\mathrm{p}=0.007)$ and the mode of transportation $(\mathrm{p}=0.04)$ with higher proportions in the HLM neighborhood (Table 1). Bus drivers reported tobacco use (33.9\%), exposure to other types of pollution (32.6\%), reported respiratory illnesses related to occupational activity (62.3\%). The bus drivers (73\%) reported to have fallen ill due to the environmental air pollution related to their professional activity. Statistically significant differences were found in bus drivers following the working area for tobacco use $(p<0.001)$, exposure to other types of pollution $(\mathrm{p}<0.001)$, and reported respiratory illnesses related to occupational activity $(\mathrm{p}<0.001)$ (Table 1$)$. A higher proportion of these variables 
Table 1. Sociodemographic characteristics of the bus drivers in the neighborhoods of HLM, Medina and Pertersen, Dakar, Senegal $\mathrm{n}=178$.

\begin{tabular}{|c|c|c|c|c|c|}
\hline Variables & $\operatorname{HLM}(\mathrm{n}=59)$ & MEDINA $(n=63)$ & PETERSEN $(\mathrm{n}=56)$ & TOTAL $(\mathrm{n}=178)$ & p-value \\
\hline Age (years) & $31.9 \pm 9.0$ & $33.8 \pm 9.4$ & $39.0 \pm 10.9$ & $34.8 \pm 10.1$ & 0.11 \\
\hline Weight (Kg) & $72.1 \pm 13.3$ & $77.5 \pm 11.8$ & $72.2 \pm 10.1$ & $74.0 \pm 12.0$ & 0.39 \\
\hline Height $(\mathrm{cm})$ & $175.1 \pm 8.0$ & $178.4 \pm 7.4$ & $177.2 \pm 9.0$ & $176.9 \pm 8.2$ & 0.40 \\
\hline $\mathrm{BMI}\left(\mathrm{Kg} / \mathrm{m}^{2}\right)$ & $23.6 \pm 4.6$ & $24.3 \pm 4.0$ & $22.9 \pm 3.4$ & $23.6 \pm 4.1$ & 0.27 \\
\hline Duration of smoking (years) & $11.2 \pm 7.3$ & $9.6 \pm 6.3$ & $15.6 \pm 10.7$ & $11.5 \pm 7.9$ & 0.31 \\
\hline Duration in the workplace (years) & $12.7 \pm 7.9$ & $11.8 \pm 6.5$ & $12.8 \pm 10.5$ & $12.4 \pm 8.3$ & $0.02^{*}$ \\
\hline Duration in the work (years) & $13.7 \pm 8.0$ & $13.9 \pm 7.9$ & $15.1 \pm 10.9$ & $14.2 \pm 9.0$ & 0.11 \\
\hline Number of working day per week & $6.7 \pm 0.9$ & $5.2 \pm 1.4$ & $5.9 \pm 1.3$ & $5.9 \pm 1.4$ & $<0.001^{* * *}$ \\
\hline Duration of transit per day (hours) & $16.2 \pm 4.4$ & $14.1 \pm 4.2$ & $15.8 \pm 2.2$ & $15.3 \pm 3.8$ & $0.007^{* *}$ \\
\hline \multicolumn{6}{|l|}{ Education level } \\
\hline None & $25(42.3)$ & $32(50.7)$ & $26(46.4)$ & $83(46.6)$ & \\
\hline Primary & $27(45.7)$ & $24(38.1)$ & $17(30.3)$ & $68(38.2)$ & 0.50 \\
\hline Secondary & $7(12)$ & $7(11.2)$ & $13(23.3)$ & $26(15.2)$ & \\
\hline \multicolumn{6}{|l|}{ Matrimonial status } \\
\hline Single & $34(57.6)$ & $28(44.4)$ & $16(28.6)$ & $78(43.8)$ & \\
\hline Married & $24(40.7)$ & $34(53.9)$ & $39(69.6)$ & $97(54.5)$ & 0.05 \\
\hline Divorced & $1(1.7)$ & $1(1.7)$ & $1(1.8)$ & $3(1.7)$ & \\
\hline \multicolumn{6}{|l|}{ Current smoking } \\
\hline Yes & $35(59.3)$ & $15(22.6)$ & $10(17.9)$ & $60(33.9)$ & \\
\hline No & $24(40.7)$ & $48(77.4)$ & $46(82.1)$ & $118(66.1)$ & $<0.001^{* * *}$ \\
\hline \multicolumn{6}{|l|}{ Transportation } \\
\hline Public transport & $59(100)$ & $57(90.4)$ & $56(100)$ & $172(96.6)$ & \\
\hline Others & $0(0)$ & $6(9.6)$ & $0(0)$ & $6(3.4)$ & $0.04^{*}$ \\
\hline \multicolumn{6}{|l|}{ Exposure to others types of pollution } \\
\hline Yes & $3(5.1)$ & $32(50.7)$ & $22(39.3)$ & $58(32.6)$ & \\
\hline No & $56(94.9)$ & $31(49.3)$ & $34(60.7)$ & $120(67.4)$ & $<0.001^{* * *}$ \\
\hline \multicolumn{6}{|l|}{ Respiratory diseases related to work } \\
\hline Yes & $50(84.7)$ & $35(55.5)$ & $26(46.4)$ & $111(62.3)$ & \\
\hline No & $9(15.3)$ & $29(44.5)$ & $30(50.3)$ & $62(37.7)$ & $<0.001^{* * *}$ \\
\hline \multicolumn{6}{|l|}{ Respiratory diseases related to air pollution } \\
\hline Yes & $56(94.9)$ & $39(61.9)$ & $35(62.5)$ & $130(73.0)$ & \\
\hline No & $3(5.1)$ & $24(38.1)$ & $21(37.5)$ & $48(27.0)$ & $<0.001^{* * *}$ \\
\hline
\end{tabular}

${ }^{*} \mathrm{p}<0.05 ;{ }^{* *} \mathrm{p}<0.01 ;{ }^{* * *} \mathrm{p}<0.001$. Values in parentheses are percentages. Abbreviations: BMI, Body mass index.

still occurred among bus drivers in the HLM neighborhood.

Bus drivers reported respiratory symptoms at $73 \%$ with significant differences proportions $(\mathrm{p}<0.001)$ according the working area such as cold, headaches, chronic cough, wheezing and dyspnea $(\mathrm{p}=0.03)$ (Table 2). Of the abnormal symptoms reported, headaches were found (53.4\%) and respiratory symptoms such as chronic cough $(57.9 \%)$, cold $(67.5 \%)$, and wheezing (62\%) with statistically significant differences $(\mathrm{p}<0.05)$ depending on their working area (Table 2$)$. The 
HLM neighborhood recorded the most complaints of respiratory symptoms (94.9\%) among the bus drivers compared to those working in the neighborhoods of Medina (61.9\%) and Petersen (62.5\%) (Table 2). Symptoms of allergic rhinitis were reported by bus drivers such as nasal congestion (82\%), nasal discharge (74.7\%), sneezing (80.9\%), and eye irritation (86\%) (Table 2). Significant differences $(\mathrm{p}<0.05)$ in the proportions of these symptoms of allergic rhinitis were observed between the working area with a predominance of these symptoms among bus drivers in the HLM neighborhood. However, there is no significant difference on the occurrence of asthma attacks in bus drivers regardless of their working area (Table 2). The pulmonary volumes and capacities measured by spirometry in bus drivers are lower than the predicted values. Statistically significant differences were found for the spirometric parameters between the bus drivers according to their working area (Table 3). Pulmonary volumes and

Table 2. Prevalence of respiratory symptoms in bus drivers in the neighborhoods of HLM, Medina and Pertersen, Dakar, Senegal $\mathrm{n}=178$.

\begin{tabular}{|c|c|c|c|c|c|}
\hline Variables & HLM $(\mathrm{n}=59)$ & Medina $(\mathrm{n}=63)$ & Petersen $(n=56)$ & Total $(\mathrm{n}=178)$ & p-value \\
\hline \multicolumn{6}{|l|}{ Reported symptoms } \\
\hline Cold & $56(94.9)$ & $27(42.9)$ & $34(60.7)$ & $117(65.7)$ & $<0.001^{* * *}$ \\
\hline Headaches & $53(89.8)$ & $15(23.8)$ & $27(48.2)$ & $95(53.4)$ & $<0.001^{* * *}$ \\
\hline Cough & $59(93.2)$ & $63(34.9)$ & $56(46.4)$ & $103(57.9)$ & $<0.001^{* * *}$ \\
\hline Weezhing & $52(88.1)$ & $26(41.3)$ & $30(53.6)$ & $108(60.7)$ & $<0.001^{* * *}$ \\
\hline Sleeping disorders & $56(94.9)$ & $39(76)$ & $34(60.7)$ & $132(74.2)$ & $<0.001^{* * *}$ \\
\hline Asthma attack & $3(5.1)$ & $4(6.3)$ & $2(3.6)$ & $9(5.1)$ & 0.97 \\
\hline Dyspnea & $57(96.6)$ & $54(85.7)$ & $43(76.8)$ & $154(86.5)$ & $0.03^{\star}$ \\
\hline Dry cough at night & $56(94.9)$ & $35(55.6)$ & $36(64.3)$ & $127(71.3)$ & $<0.001^{* * *}$ \\
\hline Sneezing & $56(94.9)$ & $42(66.7)$ & $46(82.1)$ & $144(80.9)$ & $0.001^{\star *}$ \\
\hline Nasal discharge & $52(88.1)$ & $38(60.3)$ & $43(76.8)$ & $133(74.7)$ & $0.01^{*}$ \\
\hline Nasal congestion & $59(96.6)$ & $63(71.4)$ & $56(78.9)$ & $146(82)$ & $0.007^{\star *}$ \\
\hline Eye irritation & $59(100)$ & $50(79.4)$ & $44(78.6)$ & $153(86)$ & $0.001^{\star *}$ \\
\hline Nose irration & $59(100)$ & $32(50.8)$ & $41(73.2)$ & $132(74.2)$ & $<0.001^{\star * *}$ \\
\hline
\end{tabular}

${ }^{\star} \mathrm{p}<0.05 ;{ }^{* *} \mathrm{p}<0.01 ;{ }^{* * *} \mathrm{p}<0.001$. Values in parentheses are percentages.

Table 3. Lung volumes and capacities in bus drivers in the neighborhoods of HLM, Medina and Pertersen, Dakar, Senegal $\mathrm{n}=178$.

\begin{tabular}{|c|c|c|c|c|c|c|c|c|c|c|}
\hline \multirow[b]{2}{*}{ Parameters } & \multicolumn{3}{|c|}{ HLM $(\mathrm{n}=59)$} & \multicolumn{3}{|c|}{ Medina $(\mathrm{n}=63)$} & \multicolumn{3}{|c|}{ Petersen $(n=56)$} & \multirow[b]{2}{*}{$\mathrm{p}$-value } \\
\hline & $\begin{array}{c}\text { Pre-BD } \\
(\text { Mean } \pm \text { SD })\end{array}$ & $\begin{array}{c}\text { Post-BD } \\
(\text { Mean } \pm \text { SD })\end{array}$ & $\mathrm{p}$-value & $\begin{array}{c}\text { Pre-BD } \\
(\text { Mean } \pm \text { SD })\end{array}$ & $\begin{array}{c}\text { Post-BD } \\
(\text { Mean } \pm \mathrm{SD})\end{array}$ & p-value & $\begin{array}{c}\text { Pre-BD } \\
(\text { Mean } \pm \text { SD })\end{array}$ & $\begin{array}{c}\text { Post-BD } \\
(\text { Mean } \pm \text { SD) }\end{array}$ & $\mathrm{p}$-value & \\
\hline FVC & $2.9 \pm 0.6$ & $3.1 \pm 0.8$ & 0.26 & $3.3 \pm 0.6$ & $3.4 \pm 0.6$ & $0.02^{*}$ & $3.1 \pm 0.7$ & $3.3 \pm 0.7$ & 0.1 & $<0.001^{\star * *}$ \\
\hline $\mathrm{FEV}_{1}$ & $2.7 \pm 0.5$ & $2.8 \pm 0.6$ & 0.17 & $3.0 \pm 0.5$ & $3.1 \pm 0.6$ & $0.004^{* *}$ & $2.8 \pm 0.6$ & $3.0 \pm 0.6$ & $0.03^{*}$ & $<0.001^{* * *}$ \\
\hline $\mathrm{FEV}_{1} / \mathrm{FVC}$ & $93.1 \pm 6.9$ & $92.5 \pm 7.3$ & 0.17 & $89.9 \pm 8.8$ & $91.5 \pm 7.6$ & $<0.001^{* * *}$ & $90.6 \pm 8.6$ & $91.7 \pm 7.9$ & 0.38 & $<0.001^{* * *}$ \\
\hline PEF & $7.2 \pm 1.5$ & $7.6 \pm 1.6$ & $0.02^{\star}$ & $7.7 \pm 1.6$ & $8.1 \pm 1.6$ & $0.005^{\star *}$ & $7.6 \pm 1.5$ & $7.7 \pm 1.5$ & 0.09 & $<0.001^{* * *}$ \\
\hline FEF25-75 & $4.3 \pm 1.3$ & $4.5 \pm 1.4$ & $0.02^{*}$ & $4.1 \pm 1.3$ & $4.6 \pm 1.4$ & $0.004^{\star *}$ & $4.2 \pm 1.4$ & $4.6 \pm 1.5$ & 0.10 & $<0.001^{* * *}$ \\
\hline
\end{tabular}

Abbreviations: FVC: Forced vital capacity, FEV1: Forced expiratory volume in one second, PEF: Peak expiratory flow, FEF25-75: expiratory flow from 25\% $75 \%$ of the vital capacity. ${ }^{*} \mathrm{p}<0.05 ;{ }^{* *} \mathrm{p}<0.01 ;{ }^{* *} \mathrm{p}<0.001$. 
Table 4. Frequency of respiratory illnesses diagnosed by spirometry in the neighborhoods of HLM, Medina and Pertersen, Dakar, Senegal $n=178$.

\begin{tabular}{cccccc}
\hline Diagnostic & $\begin{array}{c}\text { HLM (n= 59) } \\
\mathrm{n}(\%)\end{array}$ & $\begin{array}{c}\text { Medina (n=63) } \\
\mathrm{n}(\%)\end{array}$ & $\begin{array}{c}\text { Petersen }(\mathrm{n}=56) \\
\mathrm{n}(\%)\end{array}$ & $\begin{array}{c}\text { Total }(\mathrm{n}=178) \\
\mathrm{n}(\%)\end{array}$ & p-value \\
\hline Normal & $13(22)$ & $20(32)$ & $21(37)$ & $54(30)$ & \\
Asthma & $26(44)$ & $18(28)$ & $25(45)$ & $69(39)$ & $0.04^{*}$ \\
COPD & $20(34)$ & $25(40)$ & $10(18)$ & $55(31)$ & \\
\hline
\end{tabular}

${ }^{*} \mathrm{p}<0.05$. Values in parentheses are percentages. Abbreviations: COPD, Chronic obstructive pulmonary disease.

capacities with significant differences $(\mathrm{p}<0.05)$ between neighborhoods among bus drivers are FVC, FEV1, FEV1/FVC, DEP and DEM25-75. Pulmonary volumes and capacities are significantly increased after bronchodilatation in bus drivers (Table 3).

Lung function tests showed prevalences of asthma and COPD respectively of $38.8 \%$ and $30.3 \%$ (Table 4 ). The respiratory health status of bus drivers varies significantly according to their working area $(\mathrm{p}=0.04)$ (Table 4$)$. Thus, a higher proportion of bus drivers with normal respiratory health was determined by spirometry in Petersen (37\%), Medina (32\%) and less in HLM (22\%) (Table 4). Asthma was more common among bus drivers located in Petersen (45\%) and a higher proportion of COPD in the Medina (40\%) (Table 4). The results of the logistic regression analysis of factors associated with occupational asthma showed significant impacts of the working area, cold, family history of asthma, and wheezing which increased the risk of asthma attacks of 3 times, 6 times, 3 times and 12 times respectively among bus drivers (Table 5). However, symptoms of allergic rhinitis such as runny nose, sneezing, eye and nose irritation, and BMI did not have a significant impact of asthma in bus drivers (Table 5). The analysis of the logistic regression of factors associated with COPD showed significant impact of the presence of cold, nose irritation and low BMI which increased the occurrence of COPD of 7 times, 4 times, and 2 times respectively among bus drivers (Table 5).

\section{Discussion}

These results are similar to the findings of several studies on the effects of occupational exposure to air pollution on respiratory health. However, most studies of workers exposed to traffic air pollution have been made in traffic police because of their high exposure to this pollution. In the traffic police in Nigeria, a high prevalence of respiratory symptoms was also found [14]. A predominance of respiratory symptoms has been found in bus drivers working in the HLM neighborhood. In Dakar, data from the air quality data management center (CGQA) data showed that the measurement station located in the HLM neighborhood recorded higher concentrations of pollutants compared to other measuring stations in the city [30]. The high prevalence of respiratory symptoms in 
Table 5. Regression analysis on relationship of independent variables with asthma and COPD in the neighborhoods of HLM, Medina and Pertersen, Dakar, Senegal $\mathrm{n}=178$.

\begin{tabular}{|c|c|c|c|c|c|c|}
\hline & \multicolumn{3}{|c|}{ Asthma } & \multicolumn{3}{|c|}{ COPD } \\
\hline & \multicolumn{3}{|c|}{ OR $(95 \% \mathrm{CI})$} & \multicolumn{3}{|c|}{ OR $(95 \% \mathrm{CI})$} \\
\hline & Crude & Ajusted & $\mathrm{p}$-value & Crude & Ajusted & $\mathrm{p}$-value \\
\hline \multicolumn{7}{|l|}{ Districts } \\
\hline Medina & 1 & 1 & & 1 & 1 & \\
\hline HLM & $1.4(0.65-3.14)$ & $2.6(0.82-8.26)$ & 0.10 & $0.7(0.33-1.65)$ & $0.6(0.2-2.08)$ & 0.45 \\
\hline Petersen & $1.9(0.87-4.52)$ & $3.2(1.13-9.31)$ & $0.02^{*}$ & $0.4(0.16-0.98)$ & $0.3(0.11-1.01)$ & 0.05 \\
\hline \multicolumn{7}{|l|}{ Cold } \\
\hline No & 1 & 1 & & 1 & 1 & \\
\hline Yes & $3.1(0.81-12.51)$ & $6.3(1.12-35.79)$ & $0.03^{*}$ & $2.9(0.61-14.23)$ & $7.7(1.14-52.8)$ & $0.03^{*}$ \\
\hline \multicolumn{7}{|c|}{ Family history of asthma } \\
\hline No & 1 & 1 & & 1 & 1 & \\
\hline Yes & $2.5(1.2-5.28)$ & $2.9(1.2-7.04)$ & $0.01^{*}$ & $0.5(0.25-1.21)$ & $0.4(0.18-1.24)$ & 0.12 \\
\hline \multicolumn{7}{|l|}{ Wheezing } \\
\hline No & 1 & 1 & & 1 & 1 & \\
\hline Yes & $7.8(0.94-65.89)$ & $12.7(1.14-141.74)$ & $0.03^{*}$ & $0.2(0.03-2.07)$ & $0.1(0.01-1.75)$ & 0.13 \\
\hline \multicolumn{7}{|l|}{ Nasal discharge } \\
\hline No & 1 & 1 & & 1 & 1 & \\
\hline Yes & $1.4(0.67-3.32)$ & $2.3(0.74-7.35)$ & 0.15 & $0.7(0.34-1.78)$ & $0.6(0.19-1.92)$ & 0.38 \\
\hline \multicolumn{7}{|l|}{ Sneezing } \\
\hline No & 1 & 1 & & 1 & 1 & \\
\hline Yes & $1.1(0.77-2.75)$ & $2.8(0.83-9.75)$ & 0.09 & $0.8(0.19-1.48)$ & $0.5(0.15-2.10)$ & 0.39 \\
\hline \multicolumn{7}{|l|}{ Eye irritation } \\
\hline No & 1 & 1 & & 1 & 1 & \\
\hline Yes & $1.7(0.69-4.27)$ & $3.2(0.81-13.16)$ & 0.09 & $0.8(0.31-2.13)$ & $0.3(0.07-1.48)$ & 0.14 \\
\hline \multicolumn{7}{|l|}{ Nose irritation } \\
\hline No & 1 & 1 & & 1 & 1 & \\
\hline Yes & $0.6(0.28-1.22)$ & $0.4(0.14-1.66)$ & 0.25 & $3.7(0.96-12.8)$ & $4.4(1.19-16.7)$ & $0.02^{*}$ \\
\hline \multicolumn{7}{|l|}{ BMI } \\
\hline$\geq 23.6 \mathrm{Kg} / \mathrm{m}^{2}$ & 1 & 1 & & 1 & 1 & \\
\hline$<23.6 \mathrm{Kg} / \mathrm{m}^{2}$ & $1.8(0.7-5.12)$ & $1.8(0.83-4.22)$ & 0.13 & $2.1(1.06-4.34)$ & $2.4(1.06-5.58)$ & $0.03^{*}$ \\
\hline
\end{tabular}

${ }^{*} \mathrm{p}<0.05$.

bus drivers in the HLM neighborhood may be due to their high exposure to ambient air pollution in this area. This decline in respiratory function may be due to the effects of a large number of pollutants such as nitrogen dioxide $\left(\mathrm{NO}_{2}\right)$, fine particles (PM10 et PM2.5) and carbon monoxide (CO) from road traffic, which induce oxidative stress in the pulmonary tracts [2] [3] [4].

The prevalence of asthma reported by bus drivers is $5.1 \%$, while spirometric 
tests revealed a prevalence of $38.8 \%$. A prevalence of $4.3 \%$ of asthma (without spirometric examination) was reported by traffic police in Lagos [14]. Our results confirm the evidence in the literature that a large proportion of individuals who have asthma, are generally under diagnosed [31]. This difference can be explained by the fact that bus drivers sometimes are unaware of the carrier status of asthma. The prevalence of asthma found among bus drivers in Dakar is 2.7 times higher than that found among the urban population of Dakar. Some studies have shown that long-term exposure to pollutants from road traffic is associated with the occurrence and exacerbation of asthma [31] [32]. However, air pollution as an etiological factor in the occurrence of asthma has been demonstrated in children and remains uncertain in adults [33].

The results of the logistic regression analysis of factors associated with asthma showed that the working area, the presence of cold, a family history of asthma, and the presence of wheezing increased the risk of asthma in bus drivers. In $\mathrm{Ni}$ geria, the Ekpenyong et al. Team, 2017 [13] also showed that taxi drivers who have a high transit time due to distance traveled or traffic congestions are more likely to develop asthma. In India, it has also shown a significant association ( $\mathrm{p}=$ 0.01 ) between asthma and the existence of a family history of the disease in asthmatic patients [34].

A high prevalence of COPD (30.3\%) was also found in bus drivers. In Africa, the prevalence of COPD varies between $4 \%$ and $39 \%$. However, it is higher among workers who are frequently exposed to air pollution such as workers in industrial zones and farmers [35]. Chronic exposure to air pollution has been shown to be associated with the prevalence of COPD [36].

The analysis of the logistic regression of occupational factors with COPD showed significant impact of the presence of cold, nose irritation and low BMI on COPD in bus drivers. In England, it was also shown that COPD was significantly associated with cold and occupational exposures [37]. Bus drivers with a low BMI were more likely to have COPD. These results are similar to those of the team of Denguezli et al., 2016 [38] who found an increased risk of COPD in adults with a low BMI.

\section{Limitations of the Study}

There are some limitations to this study. First, the study could only be conducted in men because the work of bus driver is exclusively done by men in Senegal. Second, exposure to indoor air pollution has not been evaluated in bus drivers. Indoor air pollution is known to be a risk factor of chronic respiratory diseases. Third, personal exposure measurements of pollutants mainly released from cars were also not possible due to financial constraints. However, this is the first study of its kind to assess the respiratory health of bus drivers in Senegal.

\section{Conclusion}

This study showed a higher prevalence of chronic respiratory diseases and a de- 
creased lung function in bus drivers. The deterioration of their respiratory health was associated with their work environment. These results could serve as an advocacy tool for laws that could limit emissions of air pollutants from vehicles which are harmful to health. Considering that this is the first study to be conducted on the respiratory health of bus drivers in Dakar city, more studies are needed to determine if the chronic respiratory diseases observed in the bus drivers are only due to their work environment.

\section{Acknowledgements}

We thank International Development Research Centre (IDRC) for funding this work and the bus drivers for their participation.

\section{Declaration of Interests}

There is no conflict of interest in this article.

\section{References}

[1] Nejjari, C., et al. (2003) Air Pollution: A New Respiratory Risk for Cities in LowIncome Countries. International Journal of Tuberculosis and Lung Diseases, 7, 223 231.

[2] Chen, R., et al. (2011) Ambient Carbon Monoxide and Daily Mortality in Three Chinese Cities: The China Air Pollution and Health Effects Study (CAPES). Science of the Total Environment, 409, 4923-4928. https://doi.org/10.1016/j.scitotenv.2011.08.029

[3] Chen, T.M., et al. (2007) Outdoor Air Pollution: Ozone Health Effects. American Journal of Medical Sciences, 333, 244-248. https://doi.org/10.1097/MAJ.0b013e31803b8e8c

[4] Chen, T.M., et al. (2007) Outdoor Air Pollution: Particulate Matter Health Effects. American Journal of Medical Sciences, 333, 235-243. https://doi.org/10.1097/MAJ.0b013e31803b8dcc

[5] Cibella, F., et al. (2015) Effect of Indoor Nitrogen Dioxide on Lung Function in Urban Environment. Environmental Research, 138, 8-16. https://doi.org/10.1016/j.envres.2015.01.023

[6] Choudhary, H. and Tarlo, S.M. (2014) Airway Effects of Traffic-Related Air Pollution on Outdoor Workers. Current Opinion in Allergy Clinical Immunology, 14, 106-112. https://doi.org/10.1097/ACI.0000000000000038

[7] Foster, W.M., et al. (2000) Bronchial Reactivity of Healthy Subjects: 18 - 20 h Postexposure to Ozone. Journal of Applied Physiology, 89, 1804-1810. https://doi.org/10.1152/jappl.2000.89.5.1804

[8] Oh, S.M., et al. (2011) Organic Extracts of Urban Air Pollution Particulate Matter (PM2.5)-Induced Genotoxicity and Oxidative Stress in Human Lung Bronchial Epithelial Cells (BEAS-2B Cells). Mutation Research/Genetic Toxicology and Environmental Mutagenesis, 723, 142-151. https://doi.org/10.1016/j.mrgentox.2011.04.003

[9] Kurt, O.K., Zhang, J. and Pinkerton, K.E. (2016) Pulmonary Health Effects of Air Pollution. Current Opinion in Pulmonary Medicine, 22, 138-143. https://doi.org/10.1097/MCP.0000000000000248

[10] World Health Organization (WHO) (2010) Global Status Report on Noncommu- 
nicable Diseases.

[11] Baccarelli, A.A., et al. (2014) Air Pollution Exposure and Lung Function in Highly Exposed Subjects in Beijing, China: A Repeated-Measure Study. Particle and Fibre Toxicology, 11, 51. https://doi.org/10.1186/s12989-014-0051-7

[12] Patil, R.R., Chetlapally, S.K. and Bagavandas, M. (2014) Global Review of Studies on Traffic Police with Special Focus on Environmental Health Effects. International Journal of Occupational Medicine and Environmental Health, 27, 523-535. https://doi.org/10.2478/s13382-014-0285-5

[13] Ekpenyong, C.E., et al. (2012) Urban City Transportation Mode and Respiratory Health Effect of Air Pollution: A Cross-Sectional Study among Transit and NonTransit Workers in Nigeria. BMJ Open, 2. https://doi.org/10.1136/bmjopen-2012-001253

[14] Obaseki, D.O., et al. (2014) Respiratory Symptom, Lung Function and Exhaled Carbon Monoxide among a Sample of Traffic Workers in Lagos, Nigeria: A Pilot Survey. Nigerian Medicine Journal, 55, 306-309. https://doi.org/10.4103/0300-1652.137190

[15] National Agency of Health and Demography (ANSD) (2014) Demographic and Continuing Health Survey of Senegal. Ministry of Economy and Finance, Senegal.

[16] United Nations Environment Programme (UNEP) (2011) Urban Air Pollution.

[17] National Agency of Health and Demography (ANSD) (2016) Economic and Social Situation of Senegal in 2013.

[18] National Agency of Health and Demography (ANSD) (2015) Economic and Social Situation of Senegal in 2015.

[19] Hsieh, F.Y., Bloch, D.A. and Larsen, M.D. (1998) A Simple Method of Sample Size Calculation for Linear and Logistic Regression. Statistics in Medicine, 17, 1623 1634.

https://doi.org/10.1002/(SICI)1097-0258(19980730)17:14<1623::AID-SIM871>3.0.C $\underline{\mathrm{O} ; 2-\mathrm{S}}$

[20] Ferris, B.G. (1978) Epidemiology Standardization Project (American Thoracic Society). American Review of Respiratory Disease, 118, 1-120.

[21] Organization, W.H. (2003) Screening for Type 2 Diabetes. Report of a WHO and IDF Meeting. World Health Organization, Geneva.

[22] Miller, M.R., et al. (2005) General Considerations for Lung Function Testing. European Respiratory Journal, 26, 153-161. https://doi.org/10.1183/09031936.05.00034505

[23] Miller, M.R., et al. (2005) Standardisation of Spirometry. European Respiratory Journal, 26, 319-338. https://doi.org/10.1183/09031936.05.00034805

[24] Pellegrino, R., et al. (2005) Interpretative Strategies for Lung Function Tests. European Respiratory Journal, 26, 948-968. https://doi.org/10.1183/09031936.05.00035205

[25] Crapo, R.O., et al. (1982) Lung Volumes in Healthy Nonsmoking Adults. Bulletin of European Physiopathological Respiratory, 18, 419-425.

[26] Ranu, H., Wilde, M. and Madden, B. (2011) Pulmonary Function Tests. Ulster Medical Journal, 80, 84-90.

[27] Rabe, K.F., et al. (2007) Global Strategy for the Diagnosis, Management, and Prevention of Chronic Obstructive Pulmonary Disease: GOLD Executive Summary. American Journal of Respiratory and Critical Care Medicine, 176, 532-555. https://doi.org/10.1164/rccm.200703-456SO 
[28] Tarlo, S.M., et al. (2008) Diagnosis and Management of Work-Related Asthma: American College of Chest Physicians Consensus Statement. Chest, 134, 1S-41S. https://doi.org/10.1378/chest.08-0201

[29] Hosmer, D.W., Taber, S. and Lemeshow, S. (1991) The Importance of Assessing the Fit of Logistic Regression Models: A Case Study. American Journal of Public Health, 81, 1630-1635. https://doi.org/10.2105/AJPH.81.12.1630

[30] Air Quality Management Center (CGQA) (2015) Air Quality Monitoring in Dakar. Annual Report. Ministry of the Environment and Sustainable Development of Senegal.

[31] Bui, D.S., et al. (2013) Ambient Wood Smoke, Traffic Pollution and Adult Asthma Prevalence and Severity. Respirology, 18, 1101-1107. https://doi.org/10.1111/resp.12108

[32] Cai, Y., et al., (2017) Ambient Air Pollution, Traffic Noise and Adult Asthma Prevalence: A BioSHaRE Approach. European Respiratory Journal, 49.

[33] Jacquemin, B., et al. (2012) The Role of Air Pollution in Adult-Onset Asthma: A Review of the Current Evidence. Semin Respir Crit Care Med, 33, 606-619.

https://doi.org/10.1055/s-0032-1325191

[34] Davoodi, P., et al. (2015) Family History \& the Risk for Adult Onset Asthma. Indian Journal of Medical Research, 141, 361-363. https://doi.org/10.4103/0971-5916.156577

[35] Chan-Yeung, M., et al. (2004) The Burden and Impact of COPD in Asia and Africa. International Journal of Tuberculosis and Lung disease, 8, 2-14.

[36] Ko, F.W. and Hui, D.S. (2012) Air Pollution and Chronic Obstructive Pulmonary Disease. Respirology, 17, 395-401. https://doi.org/10.1111/j.1440-1843.2011.02112.x

[37] Melville, A.M., et al. (2010) COPD Prevalence and Its Association with Occupational Exposures in a General Population. European Respiratory Journal, 36, 488-493. https://doi.org/10.1183/09031936.00038309

[38] Denguezli, M., et al. (2016) COPD in Nonsmokers: Reports from the Tunisian Population-Based Burden of Obstructive Lung Disease Study. PLOS ONE, 11, e0151981. https://doi.org/10.1371/journal.pone.0151981 